\title{
Liquid-liquid extraction of cadmium(II) by TIOACI (tri-iso-octylammonium chloride) ionic liquid and its application to a TIOACl impregnated carbon nanotubes system
}

\author{
Francisco J. Alguacil ${ }^{\bowtie}$, Irene García-Díaz, Félix A. López, Olga Rodríguez \\ Centro Nacional de Investigaciones Metalúrgicas (CENIM). CSIC. Avda. Gregorio del Amo 8, 28040 Madrid, Spain \\ Corresponding author: fjalgua@cenim.csic.es
}

Submitted: 8 June 2015; Accepted: 7 September 2015; Available On-line: 5 O ctober 2015

\begin{abstract}
The extraction of cadmium(II) by the ionic liquid $\left(\mathrm{R}_{3} \mathrm{NH}^{+} \mathrm{Cl}^{-}\right)$( $\mathrm{R}$ : tri-iso-octyl) in Exxsol D100 from hydrochloric acid solution has been investigated. The extraction reaction is exothermic. The numerical analysis of metal distribution data suggests the formation of $\mathrm{R}_{3} \mathrm{NH}^{+} \mathrm{CdCl}_{3}^{-}$and $\left(\mathrm{R}_{3} \mathrm{NH}^{+}\right)_{2} \mathrm{CdCl}_{4}^{2-}$ species in the organic phase. The results obtained for cadmium(II) distribution have been implemented in an impregnated multi-walled carbon nanotubes system. The influence of aqueous solution stirring speed $\left(250-2000 \mathrm{~min}^{-1}\right)$, adsorbent dosage $(0.05-0.2 \mathrm{~g})$ and temperature $\left(20^{\circ} \mathrm{C}-60^{\circ} \mathrm{C}\right)$ on cadmium adsorption have been investigated.
\end{abstract}

KEYWORDS: Adsorption; Cadmium; Carbon nanotubes; Extraction; Hydrochloric acid; Ionic liquid

Citation / Cómo citar este artículo: Alguacil, F.J., García-Díaz, I., López, F.A., Rodríguez, O. (2015) "Liquid-liquid extraction of cadmium(II) by TIOACl (tri-iso-octylammonium chloride) ionic liquid and its application to a TIOACl impregnated carbon nanotubes system". Rev. Metal. 51(3): e051. doi: http://dx.doi.org/10.3989/revmetalm.051

RESUMEN: Extracción líquido-líquido de cadmio(II) mediante el líquido iónico ClTIOA (cloruro de tri-iso-octyl amonio) y su aplicación en un sistema de nanotubos de carbono impregnados con CITIOA. Se ha estudiado la extracción de cadmio(II), de disoluciones en medio $\mathrm{HCl}$, por el líquido iónico $\left(\mathrm{R}_{3} \mathrm{NH}^{+} \mathrm{Cl}^{-}\right)$( $\mathrm{R}$ : tri-iso-octyl) disuelto en Exxsol D100. La reacción de extracción tiene un carácter exotérmico. El análisis numérico de la distribución del metal sugiere la formación de las especies $\mathrm{R}_{3} \mathrm{NH}^{+} \mathrm{CdCl}_{3}^{-}$y $\left(\mathrm{R}_{3} \mathrm{NH}^{+}\right)_{2} \mathrm{CdCl}_{4}^{2-}$ en la fase orgánica. Estos resultados se han implementado en un sistema que utiliza nanotubos de carbono de pared múltiple impregnados con este líquido iónico. Se han investigado diversas variables experimentales: velocidad de agitación de la disolución acuosa $\left(250-2000 \mathrm{~min}^{-1}\right)$, adición del adsorbente $(0,05-0,2 \mathrm{~g})$ y temperatura $\left(20-60{ }^{\circ} \mathrm{C}\right)$.

PALABRAS CLAVE: Ácido clorhídrico; Adsorción; Cadmio; Extracción; Líquido iónico; Nanotubos de carbono

Copyright: (C) 2015 CSIC. This is an open-access article distributed under the terms of the Creative Commons Attribution-Non Commercial (by-nc) Spain 3.0 License.

\section{INTRODUCTION}

Cadmium is used in different industries such as pigments, electroplating, metallurgical products, etc., then this element could enter the water system through secondary and/or wastes, thus, and due to its toxicity, its removal from the various effluents which contained had attracted much attention both from the scientific and technological point of view.

During last years, liquid-liquid extraction of cadmium from various aqueous media has received particular interest and different reagents have been 
investigated, including acidic, basic and neutral extractants and some of their mixtures (Jha et al., 2012; Regel-Rosocka and Alguacil, 2013; Choi et al., 2014).

These extraction procedures can also be implemented in other separations processes, i.e. solidsupported liquid membrane configuration, where the performance of the separation is enhanced by the combination of extraction and stripping processes in one step (De Agreda et al., 2011). Also there is the potential application of using these extraction systems on other solid supports such as being carbon nanotubes. Carbon nanotubes are considered as materials with multiple applications, being one of the newest, its uses as adsorbent of metals (Salam et al., 2012; Mubarak et al., 2014; Alguacil et al., 2014). More interestingly, the possibility of impregnating them by suitable extractants could broad their applications in separating metals.

From the above, it is apparent that little data, if any, is available in the literature about the use of this particular ionic liquid in this role: extractant and impregnating carbon nanotubes for cadmium removal from hydrochloric acid media, thus, the present investigation was undertaken to obtain a quantitative characterization of the extraction reactions between cadmium(II) chloride solutions and the ionic liquid dissolved in a suitable organic diluent. Furthermore, a multi-walled carbon nanotubes system has been derived by using the extraction process mentioned above, and some of the parameters affecting the adsorption or ion exchange process, i.e. stirring speed of aqueous solution, adsorbent dosage and temperature, have been investigated.

\section{MATERIALS AND METHODS}

\subsection{Materials}

A $10 \mathrm{~g} \mathrm{dm}^{-3}$ stock solution of cadmium(II) was obtained by dissolving $\mathrm{CdCl}_{2}$ (Fluka) in $\mathrm{HCl}$ (Fluka), and the various aqueous solutions were obtained by the proper dilution of this in distilled water. $\mathrm{HCl}$ concentration was kept constant at $1 \mathrm{M}$ in all the experiments, as previous tests demonstrated that maximum cadmium extraction was obtained using this acid concentration.

The extractant Hostarex A324 was used as supplied by the manufacturer (Hoechst, Germany). It active substance were tri-iso-octyl amine $\left(\mathrm{R}_{3} \mathrm{~N}\right)$, and was diluted in Exxsol D100 (99\% aliphatics), Solvesso 100 (99\% aromatics) or toluene (Fluka). Exxsol D100 and Solvesso 100 are product from Exxon Chem Iberia, Spain. All other reagents were of RA grade.

The carbon nanotubes were obtained from Fluka, having the characteristics shown in Table 1.
TABLE 1. Characteristics of the carbon nanotubes

\begin{tabular}{ll}
\hline type & multi-walled \\
melting range & $3652-3697^{\circ} \mathrm{C}$ \\
density & $2.1 \mathrm{~g} \mathrm{~mL}^{-1}$ \\
appearance & dust \\
purity & $97 \%$ carbon \\
dimensions & $10 \pm 1 \mathrm{~nm}$ external diameter \\
& $4.5 \pm 0.5 \mathrm{~nm}$ internal diameter \\
& $3-6 \mu \mathrm{m}(\text { length })^{3}$ \\
maximum adsorption & $1295 \mathrm{~cm}^{3} \mathrm{~g}^{-1}$ \\
BET & $263 \mathrm{~m}^{2} \mathrm{~g}^{-1}$ \\
\hline
\end{tabular}

\subsection{Procedure}

\subsubsection{Generation of the ionic liquid}

The ionic liquid was generated by shaking equal volume phases of the corresponding organic phase and $2 \mathrm{M} \mathrm{HCl}$ solution for ten minutes at $20^{\circ} \mathrm{C}$, after phase separation, the acid content in both the equilibrated aqueous and organic solutions were checked by titration, in ethanolic medium, with standard $\mathrm{NaOH}$ solutions and using bromothymol blue as indicator. Under the above experimental conditions, the next reaction occurs:

$$
\mathrm{H}_{\mathrm{aq}}^{+}+\mathrm{Cl}_{\mathrm{aq}}^{-}+\mathrm{R}_{3} \mathrm{~N}_{\mathrm{org}} \Leftrightarrow\left(\mathrm{R}_{3} \mathrm{NH}^{+} \mathrm{Cl}^{-}\right)_{\text {org }}
$$

with generation of the ionic liquid. The subscripts aq and org refereed to the corresponding aqueous and organic phases.

\subsubsection{Liquid-liquid extraction experiments}

Distribution ratio experiments were performed at $20{ }^{\circ} \mathrm{C}$ (unless otherwise stated) by shaking $\left(700 \mathrm{~min}^{-1}\right)$ equal volumes $\left(20 \mathrm{~cm}^{3}\right)$ of the organic and aqueous phases in separatory funnels for the required time. It should be noted here that isodecanol was used as modifier of the organic solutions prepared from Exxsol D100, since using this diluent a third (an undesiderable) phase was formed after the contact of the aqueous and organic solutions. After phase separation, the metal remaining in the aqueous solution was analysed by AAS using a Perkin Elmer 1100B spectrophotometer. The amount of cadmium extracted was obtained by difference with the initial concentration in the aqueous phase. From these data, the distribution ratio, $\mathrm{D}_{\mathrm{Cd}}$, was calculated as:

$$
\log \mathrm{D}_{\mathrm{Cd}}=\log [\mathrm{Cd}]_{\mathrm{org}}-\log [\mathrm{Cd}]_{\mathrm{aq}}
$$


where $[\mathrm{Cd}(\mathrm{II})]_{\text {org }}$ and $[\mathrm{Cd}(\mathrm{II})]_{\mathrm{aq}}$ are the total equilibrium cadmium concentrations in the organic and aqueous phases, respectively.

\subsubsection{Impreganted carbon nanotubes experiments}

The impregnated carbon nanotubes were prepared by impregnating the adsorbent with a solution of $50 \% \mathrm{v} / \mathrm{v}$ of the ionic liquid in Solvesso 100. The impregnation process was carried out by gently shake of $100 \mathrm{~mL}$ of the organic solution and $1 \mathrm{~g}$ of the pristine carbon nanotubes, during 24 hours at $20^{\circ} \mathrm{C}$, after, the mixture was filtrated and washing several times with distilled water until all the excess of the organic solution was eliminated from the solid. The impregnated solid was then dry at $80^{\circ} \mathrm{C}$ until constant weight was achieved.

The batch transport experiments were carried out in a glass reactor provided of mechanical (impeller) shaking. Solution $\left(100 \mathrm{~cm}^{3}\right)$ containing cadmium(II) and $1 \mathrm{M} \mathrm{HCl}$ was used as starting solution and to this, weighed amounts of the impregnated adsorbent was added. In each adsorption experiment, the stirring rate in the aqueous solution was kept constant at $2000 \mathrm{~min}^{-1}$, unless otherwise stated. The cadmium content of the aqueous solution was periodically determined by Atomic Absorption Spectroscopy (AAS).

\section{RESULTS AND DISCUSSION}

\subsection{Liquid-liquid system}

A preliminary test was carried out to determine the time needed to achieve equilibrium. Thus, the effect of equilibration time on the extraction of cadmium(II) by the ionic liquid $\mathrm{TIOAH}{ }^{+} \mathrm{Cl}^{-}$was studied by shaking phases of the extractant $10 \% \mathrm{v} / \mathrm{v}$ in Exxsol D100 and 5\% v/v iso-decanol and an aqueous phase of $1.0 \mathrm{~g} \mathrm{~L}^{-1} \mathrm{Cd}(\mathrm{II})$ in $1 \mathrm{M} \mathrm{HCl}$ for different times at $20^{\circ} \mathrm{C}$. Equilibrium was achieved within 5 minutes of contact, though the change between 1 minute and 60 minutes was negligible $\left(\log \mathrm{D}_{\mathrm{Cd}}=2.5 \pm 0.05\right)$.

The relationship between cadmium extraction and the temperature was also studied using the same organic and aqueous solutions as described above. Table 2 shows the variation of $\log \mathrm{D}_{\mathrm{Cd}}$ and the temperature. There is a decrease of cadmium extraction

TABLE 2. Effect of the temperature on cadmium extraction

\begin{tabular}{lc}
\hline Temperature $\left({ }^{\circ} \mathbf{C}\right)$ & $\log \mathbf{D}$ \\
\hline 20 & 2.5 \\
40 & 2.3 \\
60 & 2.0
\end{tabular}

with the increase of temperature. The extraction process is therefore exothermic with $\Delta \mathrm{H}^{\circ}$ estimated as $-20 \mathrm{~kJ} \mathrm{~mol}^{-1}$.

To determine the effect of the organic diluent on the present system, extractions were carried out with solutions of $\mathrm{TIOAH}^{+} \mathrm{Cl}^{-} 10 \% \mathrm{v} / \mathrm{v}$ in each diluent and aqueous phases of $1.0 \mathrm{~g} \mathrm{~L}^{-1}$ cadmium(II) in $1 \mathrm{M} \mathrm{HCl}$. Temperature was $20^{\circ} \mathrm{C}$ and equilibration time was 10 minutes. Table 3 shows the extraction results obtained for these experiments. It can be seen that, apparently, better extraction results are obtained when aromatic diluents are used instead of Exxsol D100. Moreover, the use of aromatic diluents avoided the use of iso-decanol (modifier), since with these aromatic diluents no third phase (or second organic phase) is formed at every hydrochloric acid concentration.

The influence of initial cadmium concentration on extraction of the metal was studied at $20^{\circ} \mathrm{C}$, by shaking aqueous phases which contained different cadmium concentrations in $1 \mathrm{M} \mathrm{HCl}$ and organic phases of $\mathrm{TIOAH}^{+} \mathrm{Cl}^{-} 10 \% \mathrm{v} / \mathrm{v}$ in Exxsol D100 and $5 \% \mathrm{v} / \mathrm{v}$ iso-decanol. As it can be seen from Table 4, the variation in the initial cadmium concentration influenced the extraction of the metal, decreasing it as the initial cadmium concentration in the aqueous solution is increased, though for each initial cadmium concentration, there is no appreciable difference in metal extraction with different total chloride concentrations in the aqueous phase.

In order to estimate the composition of the extracted species, the experimental data obtained in the distribution equilibrium studies were evaluated using a computer program which searches, for a given model, the best set of equilibrium constants that would minimize the error squares sum defined by:

$$
\mathrm{U}=\sum\left(\log \mathrm{D}_{\text {exp }}-\log \mathrm{D}_{\text {calc }}\right)^{2}
$$

TABLE 3. Influence of the organic diluent on cadmium extraction

\begin{tabular}{lc}
\hline Diluent & $\log \mathbf{D}$ \\
\hline Exxsol D100 & 2.5 \\
Solvesso 100 & 3.0 \\
Toluene & 3.2 \\
\hline
\end{tabular}

${ }^{\dagger}$ and $5 \% \mathrm{v} / \mathrm{v}$ iso-decanol.

TABLE 4. Influence of the initial metal concentration on cadmium extraction

\begin{tabular}{lc}
\hline Initial metal concentration $\left(\mathbf{g ~ L}^{-\mathbf{1}}\right)$ & $\log \mathbf{D}$ \\
\hline 0.01 & 3.0 \\
1.0 & 2.5 \\
10 & 0.9
\end{tabular}


TABLE 5. Results of numerical calculation for cadmium(II) distribution

\begin{tabular}{lc}
\hline Species & $\log \mathbf{K}_{\text {ext }}$ \\
\hline $\mathrm{R}_{3} \mathrm{NH}^{+} \mathrm{CdCl}_{3}^{-}$ & $4.7 \max 5.0$ \\
$\left(\mathrm{R}_{3} \mathrm{NH}^{+}\right)_{2} \mathrm{CdCl}_{4}^{2-}$ & $4.6 \max 4.8$
\end{tabular}

where $D_{\exp }$ is the distribution coefficient of cadmium(II) determined experimentally and $D_{\text {calc }}$ is the value calculated by the program solving the mass balance equation for the metal and the extractant, assuming a particular set of species and constants. Several models with species of different stoichiometries were tried in order to investigate the possibility of finding different species which could improve the fit to the experimental data. For this particular system, the program fits the existence of two species in the cadmium-loaded organic phases; the corresponding stoichiometries are summarized in Table 5, which also shows the values of $\log \mathrm{K}_{\mathrm{ext}}$. The nature of the extracted species corresponded well to an anionexchange mechanism between the chloride ion of the ionic liquid and the anionic cadmium(II) species found in the aqueous solution, these stoichiometries compared well with those found in similar extraction systems (Regel-Rosocka and Alguacil, 2013).

\subsection{Impregnated carbon nanotubes system}

The adsorption of cadmium(II) by the ionic liquid generated from the amine Hostarex A324 and hydrochloric acid has also been studied using the carbon nanotubes technology, where the organic extractant impregnated the carbon nanotubes, and in order to expand the practical range of usage of these carbon nanotubes.

To achieve effective adsorption of cadmium(II) in this solid-liquid system, is necessary to explore the effect of the stirring speed on the percentage of metal adsorption. Very often, the adsorption of a metal onto a solid matrix depends of the resistance due to the liquid boundary layer. Similarly to other separations technology, sometimes, the magnitude of the boundary layer resistance is comparable to or even greater to other resistances. In the present investigation, stirring of the aqueous solution was carried out from 250 to $2000 \mathrm{~min}^{-1}$ (Table 6). The percentage of metal adsorption increased from 250 to $1000 \mathrm{~min}^{-1}$, and beyond that no increase in cadmium(II) adsorption was observed. Consequently, the thickness of the aqueous diffusion layer and the aqueous resistance to mass transfer were minimized and the diffusion contribution of the aqueous species to the mass transfer process is assumed to be constant.

Studying the effect of the temperature on the metal adsorption it was revealed that this adsorption increased with the increase of the temperature (Table 7), thus, under these experimental
TABLE 6. Influence of stirring speed on adsorption of cadmium(II)

\begin{tabular}{lc}
\hline Stirring speed $\left(\mathbf{m i n}^{-1}\right)$ & Cadmium adsorption \\
\hline 250 & 48.5 \\
500 & 58.0 \\
1000 & 70.5 \\
2000 & 70.5 \\
\hline
\end{tabular}

Aqueous phase: $0.01 \mathrm{~g} \mathrm{~L}^{-1} \mathrm{Cd}$ in $1 \mathrm{M} \mathrm{HCl}$. Adsorbent dosage: 0.2 g. Temperature: $20^{\circ} \mathrm{C}$

${ }^{\dagger}$ After 1 hour.

TABLE 7. Influence of temperature on adsorption of cadmium(II)

\begin{tabular}{lccc}
\hline Temperature $\left({ }^{\circ} \mathbf{C}\right)$ & $\begin{array}{c}\text { Cadmium } \\
\text { adsorption }(\%)\end{array}$ & $\begin{array}{c}{[\mathbf{C d}]} \\
\left(\mathbf{m g ~ L}^{-1}\right)\end{array}$ & $\begin{array}{c}{[\mathbf{C d}]} \\
\left(\mathbf{m g ~ g}^{-1}\right)\end{array}$ \\
\hline 20 & 70.5 & 3.0 & 3.5 \\
40 & 92.5 & 0.75 & 4.6 \\
60 & 98.5 & 0.15 & 4.9 \\
\hline
\end{tabular}

Aqueous phase: $0.01 \mathrm{~g} \mathrm{~L}^{-1} \mathrm{Cd}$ in $1 \mathrm{M} \mathrm{HCl}$. Adsorbent dosage: $0.2 \mathrm{~g}$. Time: 1 hour.

conditions, the removal of cadmium from the solution has an endothermic character, with $\Delta \mathrm{H}^{\circ}$ estimated as $66 \mathrm{~kJ} \mathrm{~mol}^{-1}$.

Also, the effect of adsorbent dosage on cadmium adsorption was studied. Table 8 shows percentage of adsorption values for the removal of cadmium through carbon nanotubes impregnated with $50 \% \mathrm{v} / \mathrm{v}$ of the ionic liquid in Solvesso 100. It can be seen that the percentage of adsorption increased with the adsorbent, showing table the corresponding metal uptakes and cadmium equilibrium concentrations.

Comparison of the above results with these obtained when pristine carbon nanotubes were used as adsorbent of cadmium from $1 \mathrm{M} \mathrm{HCl}$ solution shown, that under this acidic conditions, cadmium is not adsorbed or removed from the aqueous solution using the pristine material, thus, the effectiveness of impregnating it with this ionic liquid is fully demonstrated.

In order to analyze the adsorption rate of cadmum(II) onto the impregnated carbon nanotubes,

TABLE 8. Influence of carbon nanotubes dosage on adsorption of cadmium(II)

\begin{tabular}{lccc}
\hline Dosage (g) & Adsorption (\%) & $\mathbf{[ C d}]\left(\mathbf{m g ~ L}^{-\mathbf{1}}\right)$ & $\left.\mathbf{[ C d}] \mathbf{~} \mathbf{m g ~ g}^{\mathbf{- 1}}\right)$ \\
\hline 0.05 & 36.5 & 6.4 & 7.3 \\
0.1 & 59.0 & 4.1 & 5.9 \\
0.2 & 89.0 & 1.1 & 4.5 \\
\hline
\end{tabular}

Aqueous phase: $0.01 \mathrm{~g} \mathrm{~L}^{-1} \mathrm{Cd}$ in $1 \mathrm{M} \mathrm{HCl}$. Temperature: $20^{\circ} \mathrm{C}$. Time: 2 hours 
TABLE 9. Rate constants and data fit for the adsorption of cadmium(II) onto the impregnated carbon nanotubes

\begin{tabular}{llc}
\hline Model & \multicolumn{1}{c}{$\mathbf{k}$} & $\mathbf{R}^{2}$ \\
\hline pseudo-first order & $0.039 \mathrm{~min}^{-1}$ & 0.9941 \\
pseudo-second order & $0.007 \mathrm{~g} \mathrm{mg}^{-1} \mathrm{~min}^{-1}$ & 0.9954 \\
\hline
\end{tabular}

the pseudo-first order (Eq. (4)) and the pseudosecond order (Eq. (5)) rate models were used:

$$
\begin{gathered}
\ln \left(\mathrm{q}_{\mathrm{e}}-\mathrm{q}_{\mathrm{t}}\right)=\ln \left(\mathrm{q}_{\mathrm{e}}\right)-\mathrm{k}_{1} \mathrm{t} \\
\frac{\mathrm{t}}{\mathrm{q}_{\mathrm{t}}}=\frac{1}{\mathrm{k}_{2} \mathrm{q}_{\mathrm{e}}^{2}}+\frac{\mathrm{t}}{\mathrm{q}_{\mathrm{e}}}
\end{gathered}
$$

where $k_{1}$ and $k_{2}$ are the rate constants for each model, $\mathrm{q}_{\mathrm{t}}$ and $\mathrm{q}_{\mathrm{e}}$ are the metal uptake per unit mass of the adsorbent at an elapsed time and at equilibrium, respectively, and $t$ is the elapsed time.

The results from these simulations are shown in Table 9. As can be seen from these results (very similar $\mathrm{R}^{2}$ values), the kinetic adsorption of cadmium(II) can be represented well by the two models.

It should be noted here that in these impregnated systems, as in solid supported liquid membrane experimentation (Alguacil et al., 2004; Alonso et al., 2006), the nature of the extracted species has not been determined, since it is broadly accepted that it should be the same that those findings in conventional liquidliquid extraction systems, see Table 5 for the present system.

\section{CONCLUSIONS}

The ionic liquid $\left(\mathrm{R}_{3} \mathrm{NH}^{+} \mathrm{Cl}^{-}\right)$can extract cadmium(II) from hydrochloric acid media. There is a decrease in cadmium extraction with increasing temperature, so that the extraction is exothermic. Metal extraction is dependent on the metal concentration and the organic diluent. On the basis of a computer simulation model, cadmium(II) extraction by this ionic liquid can be explained by an anion exchange reaction with the formation of two metal-extractant species in the organic solution.

The extraction system has been implemented in an impregnated carbon nanotubes system in which, under the investigated experimental conditions, the metal adsorption is dependent on the stirring speed of the aqueous solution (up to $1000 \mathrm{~min}^{-1}$ ). This adsorption increases with the increase of the adsorbent dosage and with the temperature, the latter being attributable to an endothermic reaction with estimated $\Delta \mathrm{H}^{\circ}=66 \mathrm{~kJ} \mathrm{~mol}^{-1}$.

Metal adsorption can be represented either by the pseudo-first or the pseudo-second order models.

\section{ACKNOWLEDGEMENTS}

Dra. Irene García-Díaz expresses her gratitude to the Ministry of Economy and Competitiveness of Spain for their Postdoctoral Junior Grants (Ref. FPDI-2013-16391).

\section{REFERENCES}

Alguacil, F.J., López-Delgado, A., Alonso, M., Sastre, A.M. (2004). The phosphine oxide Cyanex 921 and Cyanex 923 as carriers for facilitated transport of chromium(VI)-chloride aqueous solutions. Chemosphere 57 (8), 813-819. http:// dx.doi.org/10.1016/j.chemosphere.2004.07.019.

Alguacil, F.J., Cerpa, A., Lado, I., López, F.A. (2014). Technologies for the 21 st century: carbon nanotubes as adsorbents of metals. Rev. Metal. 50 (3), e025, http://dx.doi.org/10.3989/ revmetalm. 025 .

Alonso, M., López-Delgado, A., Sastre, A.M., Alguacil, F.J. (2006). Kinetic modelling of the facilitated transport of cadmium(II) using Cyanex 923 as ionophore. Chem. Eng. J. 118 (3), 213-219. http://dx.doi.org/10.1016/j.cej. 2006.02.006.

Choi, S.-Y., Nguyen, V.T., Lee, J.-C., Kang, H., Panley, B.D. (2014). Liquid-liquid extraction of Cd(II) from pure and Ni/Cd acidic chloride media using Cyanex 921: A selective treatment of hazardous leachate of spent Ni-Cd batteries. J. Hazard. Mater. 278, 258-266. http://dx.doi.org/10.1016/j. jhazmat.2014.06.013.

De Agreda, D., García-Díaz, I., López, F.A., Alguacil, F.J. (2011). Supported liquid membrane technologies in metals removal from liquid effluents. Rev. Metal. 47 (2), 146-168. http://dx.doi.org/10.3989/revmetalmadrid.1062.

Jha, M.K., Kumar, V., Jeong, J., Lee, J.-C. (2012). Review on solvent extraction of cadmium from various solutions. Hydrometallurgy 111-112, 1-9. http://dx.doi.org/10.1016/j. hydromet.2011.09.001.

Mubarak, N.M., Sahu, J.N., Abdullah, E.C., Jayakumar, N.S. (2014). Removal of heavy metals from wastewater using carbon nanotubes. Sep. Purif. Rev. 43 (4), 311-338. http:// dx.doi.org/10.1080/15422119.2013.821996.

Regel-Rosocka, M., Alguacil, F.J. (2013). Recent trends in metals extraction. Rev. Metal. 49 (4), 292-316. http:// dx.doi.org/10.3989/revmetalm.1344.

Salam, M.A., Al-Zhrani, G., Kosa, S.A. (2012). Simultaneous removal of copper(II), lead(II), zinc(II) and cadmium(II) from aqueous solutions by multi-walled carbon nanotubes. CR Chim. 15 (5), 398-408. http://dx.doi.org/10.1016/j.crci. 2012.01.013. 